\title{
Integrated System for Traction and Battery Charging of Electric Vehicles with Universal Interface to the Power Grid
}

\author{
Tiago J. C. Sousa ${ }^{1}$, Vítor Monteiro ${ }^{1}$ and João L. Afonso ${ }^{1}$ \\ ${ }^{1}$ Centro ALGORITMI, University of Minho, Campus de Azurém, Guimarães, Portugal \\ \{tsousa | vmonteiro $\mid$ jla\}@dei.uminho.pt
}

\begin{abstract}
This paper proposes an integrated system for traction and battery charging of electric vehicles (EVs) with universal interface to the power grid. In the proposed system, the power electronics converters comprising the traction drive system are also used for the battery charging system, reducing the required hardware, meaning the integrated characteristic of the system. Besides, this interface is universal, since it can be performed with the three main types of power grids, namely: (1) Single-phase AC power grids; (2) Three-phase AC power grids; (3) DC power grids. In these three types of interfaces with the power grid, as well as in the traction drive operation mode, bidirectional operation is possible, framing the integration of this system into an EV in the context of smart grids. Moreover, the proposed system endows an EV with an on-board fast battery charger, whose operation allows either fast or slow battery charging. The main contributes of the proposed system are detailed in the paper, and simulation results are presented in order to attain the feasibility of the proposed system.
\end{abstract}

Keywords: Electric Vehicles; Traction Drive Systems; Battery Charging Systems; Smart Grids.

\section{Introduction}

Electrical energy is an essential asset for the well-being of the present modern society, whose consumption has been increasing from decade to decade. This increase led to a fossil fuels shortage, as well as augmented levels of atmospheric pollution. In order to diminish the referred consequences, electric vehicles (EVs) appear as a sustainable alternative at the utilization level, which is proved by the growing stringency on the environmental laws concerning the emission of pollutant particles by internal combustion engine vehicles [1][2].

The suitability of EVs is not only related to the mobility paradigm, but is also related to the energy management in smart grids. Besides performing the normal battery charging operation (grid-to-vehicle - G2V), which should be performed in a rationalized manner to avoid power grid congestion [3]-[8], an EV can also be employed to deliver energy to the power grid, performing support functionalities (vehicle-to-grid - V2G), which can be accomplished with a bidirectional battery charger, either on-board or off-board [9]. Besides V2G, several operation modes for 
EVs in a context of smart grids can be found in the literature, such as: vehicle-to-home $(\mathrm{V} 2 \mathrm{H})$, where the EV battery charger operates as an isolated voltage source; home-to-vehicle $(\mathrm{H} 2 \mathrm{~V})$, where the EV battery charger adapts its charging current in order to level the current consumed in the home where it is plugged-in; and vehicle-for-grid (V4G), where the EV battery charger operates as an active power conditioner, producing reactive power and/or harmonic currents in order to maintain high levels of power quality from the home point of view [10]-[14]. Moreover, EVs can be applied to interface renewable energy sources with the power grid, which is in accordance with the distributed generation paradigm implicit in smart grids [15][16].

Besides the battery charging operation, any EV must perform a traction operation in order to control its electric motor speed or torque. Since both consist of bidirectional AC-DC and DC-DC power electronics converters, these two systems can be combined into a single set of power electronics converters, establishing an integrated system for traction and battery charging [17]-[19]. This approach allows the EV to be equipped with an on-board fast battery charger, capable of operating with power levels that are usually found only in off-board battery chargers, besides reducing the hardware of the EV [20]. Many examples of integrated systems for traction and battery charging can be found in the literature [21]-[29], either using external inductors or the motor stator windings as the coupling inductors with the power grid. Some approaches use an auxiliary motor instead of external inductors, which is not desirable, since it increases the weight and volume of the system. Besides, the proposed approaches are limited in terms of operating modes and their interface is restricted to a single type of power grid. Taking into account these limitations, this paper proposes an integrated system for traction and battery charging of EVs with a universal interface with the power grid, which means that the battery charging operation can be accomplished with the connection to the three main types of power grids, namely: (1) Single-phase AC power grids; (2) Three-phase AC power grids; (3) DC power grids. Bidirectional operation is possible in these three types of interfaces with the power grid, i.e., the $\mathrm{G} 2 \mathrm{~V}$ and $\mathrm{V} 2 \mathrm{G}$ operation modes are possible in the three power grid types. The traction drive operation mode also comprises bidirectional operation, i.e., the system is able to perform regenerative braking when the EV motor acts as a generator, returning the generated energy back to the batteries.

The rest of the paper is structured as follows. Section 2 describes the relationship of the proposed system with industrial and service systems. Section 3 describes the proposed integrated system for traction and battery charging of EVs with universal interface to the power grid, with simulation results for the referred operation modes. Finally, Section 4 outlines the main conclusions of the proposed work.

\section{Relationship to Industrial and Service Systems}

When equipped with an on-board slow battery charger that comprises bidirectional operation, an EV is capable of operating as an active power conditioner, such as a shunt active power filter, and as an isolated voltage source, such as an uninterruptible power supply (UPS). However, for the typical on-board battery chargers, these functionalities are only valid in low power installations (e.g., domestic installations). 
As aforementioned, the proposed integrated system is able to operate as an on-board fast battery charger for EVs. Besides, it can operate in bidirectional mode in single-phase AC power grids, three-phase AC power grids and DC power grids. Therefore, since the nominal power of the on-board battery charger is higher than the typical values found in traditional on-board battery chargers, an EV equipped with the proposed system is able to operate as a shunt active power filter or UPS in industrial facilities. These functionalities can provide support to an industrial facility without the need of acquiring dedicated hardware, i.e., a shunt active power filter or a UPS, since the EV can perform the same functionalities when parked in the facility. The compensation of power quality problems related with currents (e.g., harmonic distortion, unbalance and reactive power) is relevant in the sense that industries can suffer large economic losses due to poor levels of power quality, as referred in several studies [30][31]. Moreover, the operation as UPS is also relevant in an industrial context, since power outages disrupt completely the production of the facility, which can be reflected in economic losses even higher than the previous case. In this way, the proposed integrated system has a relevant role in industrial systems, despite being an electric mobility solution.

\section{Proposed System}

Fig. 1 shows a block diagram of the proposed integrated system for traction and battery charging of EVs with universal interface to the power grid. As it can be seen, the proposed system is able to interface the EV batteries with the EV motor, a

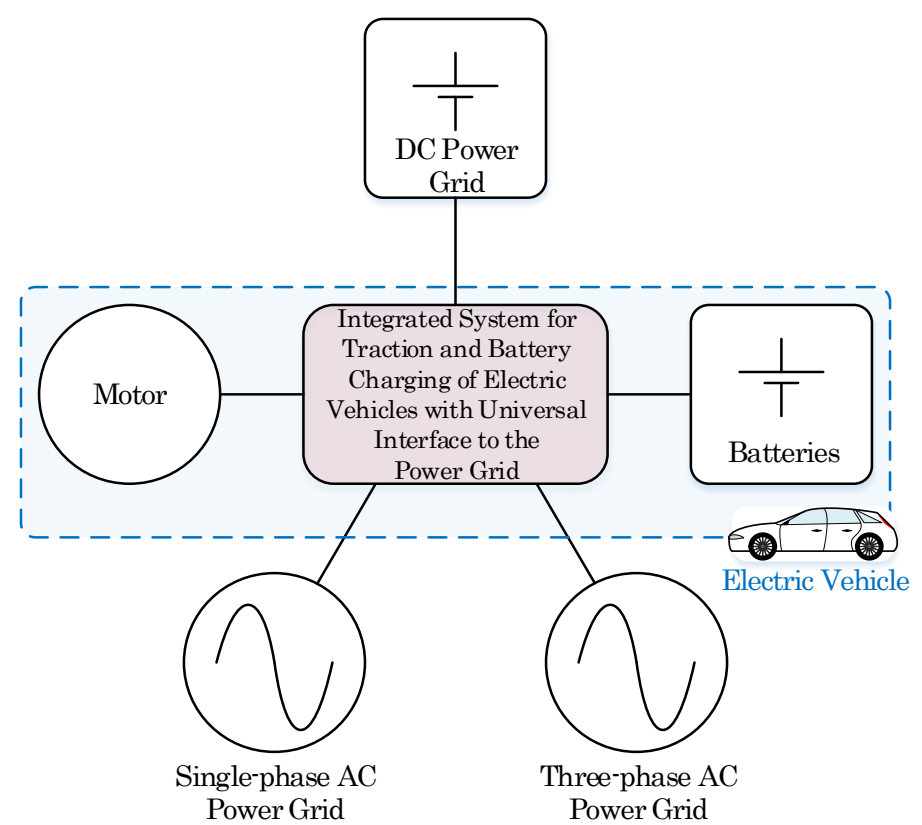

Fig. 1. Block diagram of the proposed integrated system for traction and battery charging of EVs with universal interface to the power grid. 
single-phase AC power grid, a three-phase AC power grid and a DC power grid, keeping in consideration that a single set of power electronics converters is used for all the operation modes. In order to validate the feasibility of the proposed system, simulation results were obtained in the software PSIM v9.1 and are analyzed in this section, which is divided in four subsections: (1) Traction drive system; (2) Interface with a three-phase AC power grid; (3) Interface with a single-phase AC power grid; (4) Interface with a DC power grid. The bidirectional operation of the system is analyzed in all four cases. In the scope of this paper, only the G2V and V2G operation modes are analyzed regarding the interface of the system with the different types of power grid. The battery voltage was established as $200 \mathrm{~V}$ for all cases, with an internal resistance of $0.1 \Omega$.

\subsection{Traction Drive System}

Fig. 2 shows a block diagram of the integrated system in the traction drive operation mode. In this operation mode, the integrated system establishes an interface between the EV batteries and the EV motor. During the normal traction operation, the integrated system uses the energy stored in the batteries and transfers it to the motor, controlling its speed or torque to perform the EV movement. On the other hand, when the EV experiences a downhill, or when it decelerates, the electric motor acts as a generator. The integrated system detects this transition and starts the regenerative braking operation mode, which consists of transferring the energy generated by the motor back to the batteries, extending the EV range.

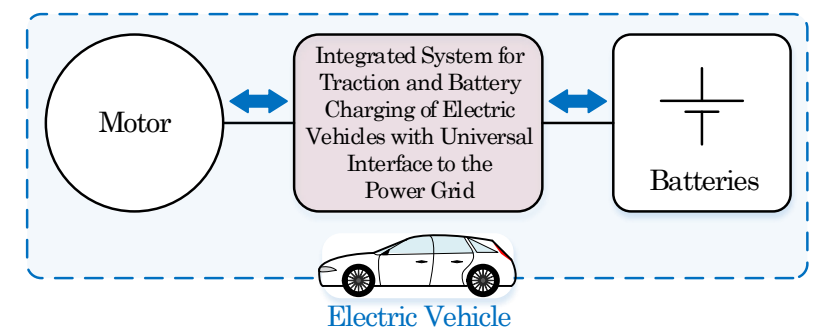

Fig. 2. Block diagram of the proposed system in traction drive operation mode.

Fig. 3 shows the operation of the integrated system in the traction drive operation mode, illustrating the two aforementioned cases. This figure shows the two cases in terms of currents in the motor stator windings $\left(i_{a}, i_{b}, i_{c}\right)$, the rotor mechanical speed $\left(n_{m}\right)$, the developed torque $\left(T_{m}\right)$ and the battery current $\left(i_{B A T}\right)$. It should be mentioned that although the motor used in the simulation is an induction motor, the proposed system is not confined to a certain motor type. The implemented controller for this operation mode was the field-oriented control (FOC). In order to control the battery current, a deadbeat predictive control was used.

The simulation results of the normal traction operation of the integrated system can be seen in Fig. 3 (a). For this operation, a reference mechanical speed of $500 \mathrm{rpm}$ was established for the motor, connected to a constant torque load of $100 \mathrm{Nm}$. It can be seen that the mechanical speed increases steadily until the desired reference value, 
with the motor torque matching the load torque in steady-state. Also, the current $i_{B A T}$ has a negative value, meaning that the batteries are discharging in order to supply energy to the motor.

Fig. 3 (b) shows the system operation during regenerative braking for the same reference speed of $500 \mathrm{rpm}$. In this case, a constant torque load of $-100 \mathrm{Nm}$ was used, with the negative sign meaning that the load drives the motor. It can be seen that the mechanical speed presents a similar behavior than the previous case. On the other hand, the torque developed by the motor is positive in the beginning, i.e., while the motor speed does not reach its reference, being negative in steady-state due to the selected value of $-100 \mathrm{Nm}$, i.e., operation as a generator. Accordingly, the current $i_{B A T}$ is positive in this case, meaning that the batteries are being charged with the energy generated by the motor. Moreover, in both modes is guaranteed the operation with sinusoidal, balanced stator currents, as well as low ripple in the mechanical speed, torque and battery current.

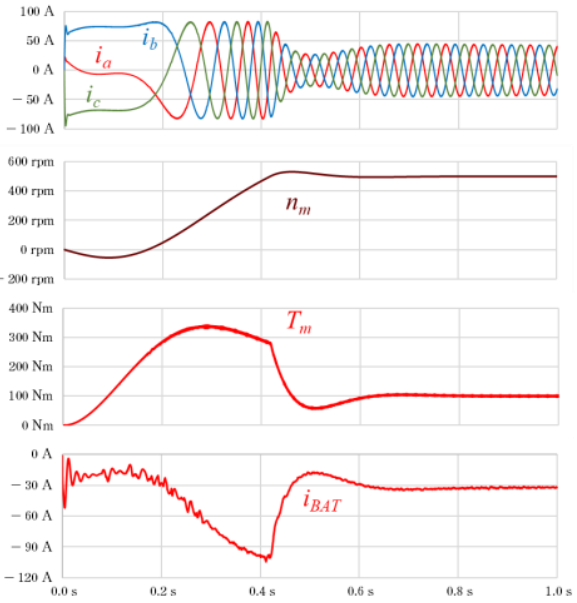

(a)

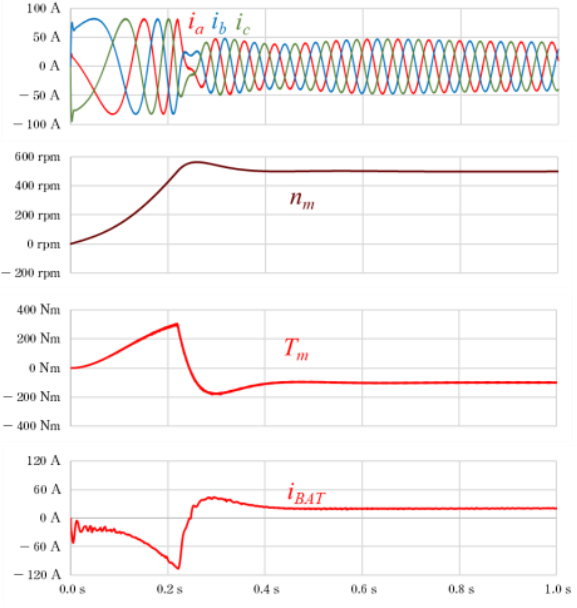

(b)

Fig. 3. Simulation results of the proposed system in the traction drive operation mode: (a) Normal traction operation; (b) Regenerative braking operation.

\subsection{Interface with a Three-phase AC Power Grid}

Fig. 4 shows a block diagram of the integrated system during the interface with a three-phase AC power grid. In this operation mode, the integrated system establishes an interface between the EV batteries and a three-phase AC power grid, enabling the charging or discharging of the batteries. During the battery charging operation $(\mathrm{G} 2 \mathrm{~V})$, the integrated system absorbs energy from the power grid, with sinusoidal, balanced currents and high power factor, and transfers it to the batteries, with controlled current or voltage. On the other hand, during the battery discharging operation (V2G), the integrated system uses the energy stored in the batteries, with controlled current or 
power, and injects it into the power grid, with sinusoidal, balanced currents and high power factor, preserving the power quality of the electrical installation.

Fig. 5 depicts the operation of the integrated system interfacing a $400 \mathrm{~V}, 50 \mathrm{~Hz}$ three-phase AC power grid, illustrating the two aforementioned operation modes. This figure shows the two cases in terms of voltages $\left(v_{a}, v_{b}, v_{c}\right)$ and currents in the power grid $\left(i_{a}, i_{b}, i_{c}\right)$ and the battery current $\left(i_{B A T}\right)$. A deadbeat predictive control was used for the current control both at the grid side and at the batteries side.

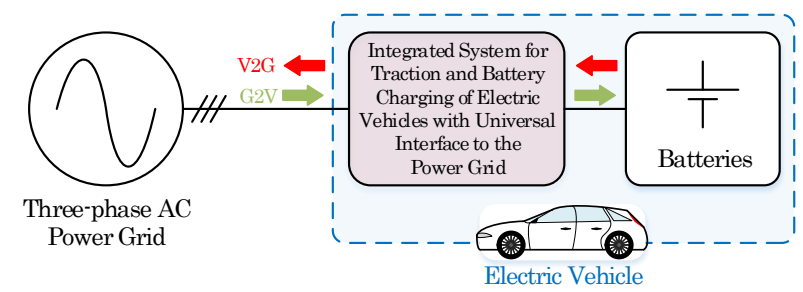

Fig. 4. Block diagram of the proposed system interfacing with a three-phase AC power grid.

The simulation results of the battery charging $(\mathrm{G} 2 \mathrm{~V})$ operation of the integrated system can be seen in Fig. 5 (a). For this operation, a battery reference current of $100 \mathrm{~A}$ was established, whose high value corresponds to a fast battery charging operation $(20 \mathrm{~kW})$. In this case, the current $i_{B A T}$ has a positive value, meaning that the batteries are being charged. Furthermore, the grid currents are sinusoidal independently of the grid voltages, presenting a total harmonic distortion (THD) of $0.8 \%$ even with a THD of $3.7 \%$ in the grid voltages. Besides a low THD, these currents are balanced and each of them is in phase with the respective grid voltage, achieving a unitary power factor.

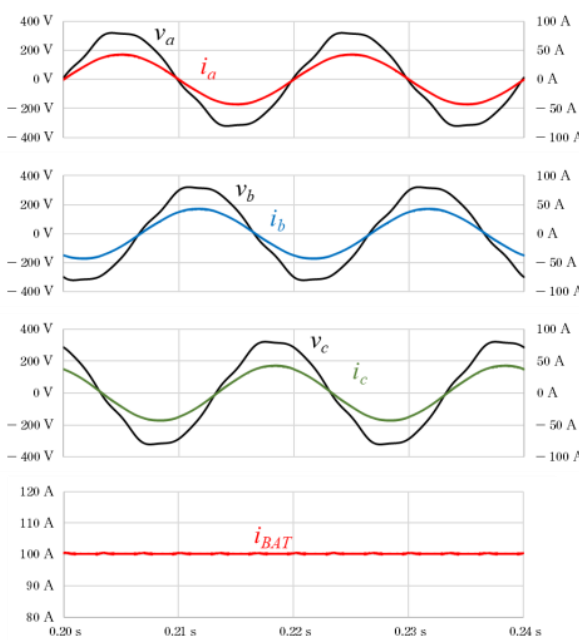

(a)

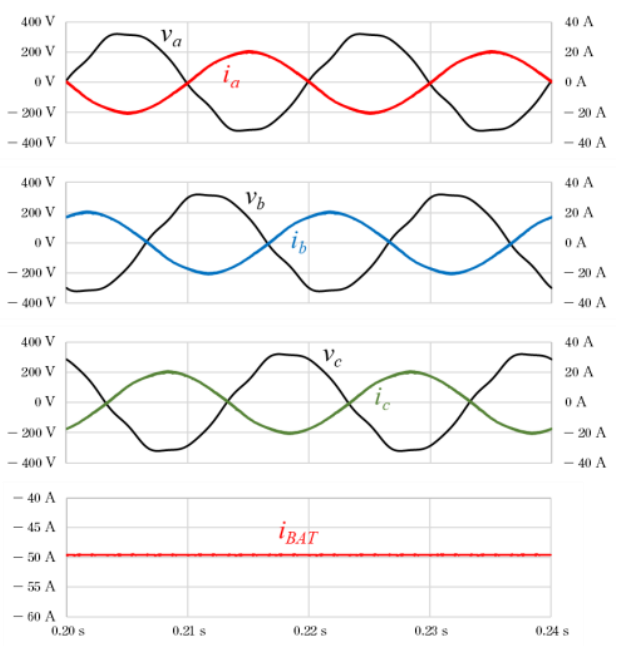

(b)

Fig. 5. Simulation results of the proposed system during the interface with a three-phase AC power grid: (a) G2V operation; (b) V2G operation. 
Fig. 5 (b) shows the system operation for the battery discharging (V2G) mode. In this case, a battery reference current of -50 A was used, with the negative sign meaning that the batteries are being discharged. As it can be seen, the current $i_{B A T}$ follows the mentioned reference value. On the other hand, the grid currents are in phase opposition with the respective voltages, meaning that the integrated system is operating as a power source, injecting energy into the power grid. As in the previous case, the grid currents are sinusoidal, with a THD of $1.8 \%$, and balanced. Therefore, both the G2V and V2G operation modes are performed assuring high levels of power quality for the three-phase AC power grid.

\subsection{Interface with a Single-phase AC Power Grid}

Fig. 6 shows a block diagram of the integrated system during the interface with a single-phase AC power grid. In this case, the integrated system establishes an interface between the EV batteries and a single-phase AC power grid, enabling the charging or discharging of the batteries. Similarly to the previous operation mode, during the battery charging operation $(\mathrm{G} 2 \mathrm{~V})$, the integrated system absorbs energy from the power grid with a sinusoidal current in phase with the grid voltage, and transfers it to the batteries, with controlled current or voltage. On the other hand, during the battery discharging operation (V2G), the integrated system uses the energy stored in the batteries with controlled current or power, and injects it into the power grid via a sinusoidal current in phase opposition with the grid voltage, preserving the power quality of the electrical installation.

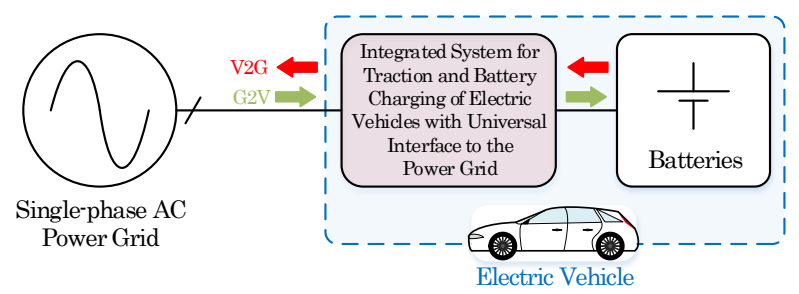

Fig. 6. Block diagram of the proposed system interfacing with a single-phase AC power grid.

Fig. 7 depicts the operation of the integrated system interfacing a $230 \mathrm{~V}, 50 \mathrm{~Hz}$ single-phase AC power grid, illustrating the two aforementioned operation modes. This figure shows the two cases in terms of voltage $\left(v_{g}\right)$ and current in the power grid $\left(i_{g}\right)$ and the battery current $\left(i_{B A T}\right)$. Similarly to the three-phase AC power grid interface, a deadbeat predictive current control was used both at the grid side and at the batteries side in order to control these currents.

The simulation results of the battery charging (G2V) operation of the integrated system can be seen in Fig. 7 (a). For this operation, a battery reference current of $30 \mathrm{~A}$ was established, corresponding to a slow battery charging operation $(6 \mathrm{~kW})$. Accordingly, the current $i_{B A T}$ has a positive value, meaning that the batteries are being charged. Moreover, the current $i_{g}$ is sinusoidal independently of the voltage $v_{g}$ and is in phase with the latter, achieving a practically unitary power factor. 
Fig. 7 (b) shows the system operation for the battery discharging (V2G) mode. In this case, a battery reference current of $-10 \mathrm{~A}$ was used, with the negative sign meaning that the batteries are being discharged. As it can be seen, the current $i_{B A T}$ follows the mentioned reference value. On the other hand, the current $i_{g}$ is sinusoidal and in phase opposition with the voltage $v_{g}$, meaning that the integrated system is operating as a power source, injecting energy into the power grid and, once again, with a unitary power factor. Therefore, as verified in the interface with a three-phase $\mathrm{AC}$ power grid, both the $\mathrm{G} 2 \mathrm{~V}$ and $\mathrm{V} 2 \mathrm{G}$ operation modes are performed assuring high levels of power quality for the single-phase AC power grid.

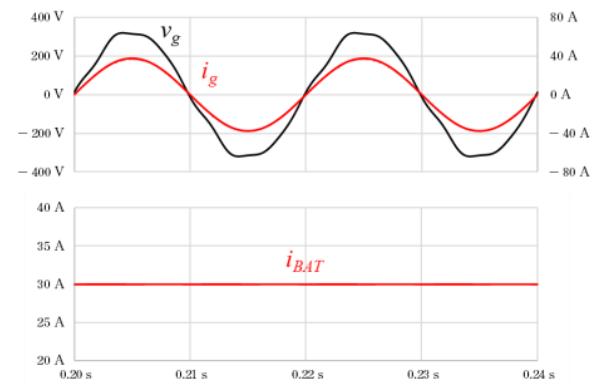

(a)

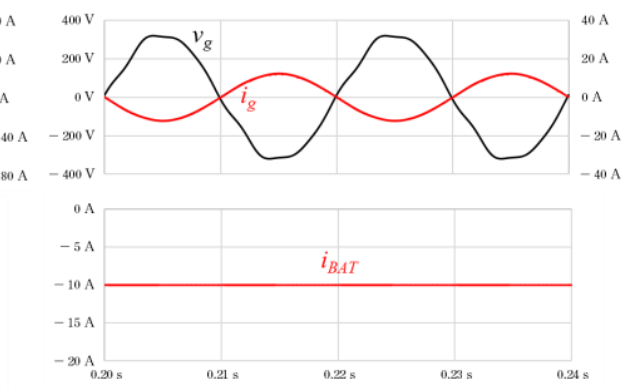

(b)

Fig. 7. Simulation results of the proposed system during the interface with a single-phase AC power grid: (a) G2V operation; (b) V2G operation.

\subsection{Interface with a DC Power Grid}

Fig. 8 shows a block diagram of the integrated system during the interface with a DC power grid. In this case, the integrated system establishes an interface between the EV batteries and a DC power grid, enabling the charging or discharging of the batteries. Similarly to the previous operation modes, during the battery charging operation $(\mathrm{G} 2 \mathrm{~V})$, the integrated system absorbs energy from the power grid and transfers it to the batteries, with controlled current or voltage. On the other hand, during the battery discharging operation (V2G), the integrated system uses the energy stored in the batteries, with controlled current or power, and injects it into the power grid, with controlled current. The main difference between this interface and the previous ones is the power quality requirements, provided that there is no reactive power in DC. Therefore, the main challenge of the system is to assure low levels of current ripple in both the grid current and the battery current. The current controllers are also of the deadbeat predictive type at both sides.

Fig. 9 depicts the operation of the integrated system interfacing a $48 \mathrm{~V} \mathrm{DC}$ power grid, illustrating the two aforementioned operation modes. This figure shows the grid current $\left(i_{D C}\right)$ and the battery current $\left(i_{B A T}\right)$. The possibility of connecting the proposed system to a low-voltage DC power grid is attractive in the future scenario of DC homes, being possible to charge the EV batteries from a power grid with a lower voltage than the batteries voltage. 


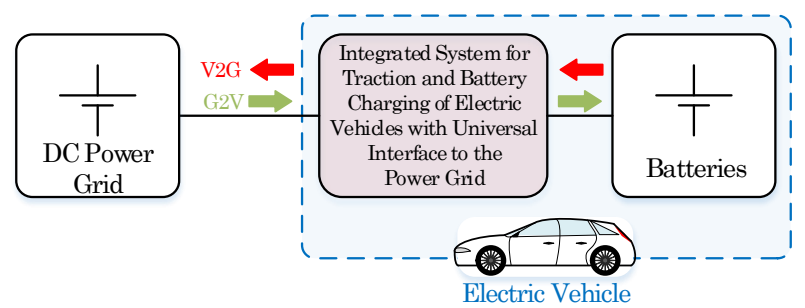

Fig. 8. Block diagram of the proposed system interfacing with a DC power grid.

The simulation results of the battery charging $(\mathrm{G} 2 \mathrm{~V})$ operation of the integrated system can be seen in Fig. 9 (a). For this operation, a battery reference current of $100 \mathrm{~A}$ was established, corresponding to a fast battery charging operation $(20 \mathrm{~kW})$. Accordingly, the current $i_{B A T}$ has a positive value, meaning that the batteries are being charged. The current $i_{D C}$ has also a positive value, since the DC power grid provides energy to the batteries. The value of the current $i_{D C}$ is relatively high $(437 \mathrm{~A})$ due to the voltage step-up operation (from $48 \mathrm{~V}$ to $200 \mathrm{~V}$ ), so that the power is practically the same both in the grid side and in the batteries side.

Fig. 9 (b) shows the system operation for the battery discharging (V2G) mode. In this case, a battery reference current of $-10 \mathrm{~A}$ was used, with the negative sign meaning that the batteries are being discharged. As it can be seen, the current $i_{B A T}$ follows the mentioned reference value. Similarly, the current $i_{D C}$ is also negative, meaning that the DC power grid is absorbing energy from the batteries. As in the previous case, the current $i_{D C}$ is higher than the current $i_{B A T}$ due to the voltage step-up operation of the integrated system.

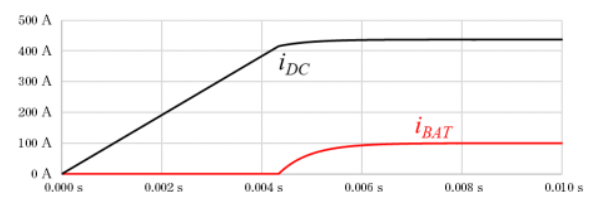

(a)

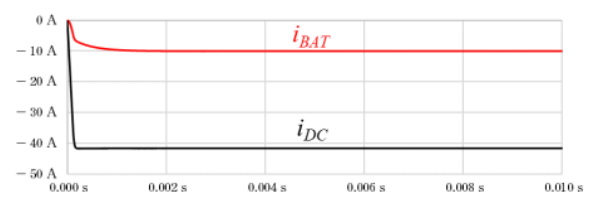

(b)

Fig. 9. Simulation results of the proposed system during the interface with a DC power grid: (a) G2V operation; (b) V2G operation.

\section{Conclusions}

This paper proposed an integrated system for traction and battery charging of electric vehicles (EVs) with a universal interface with the power grid. The proposed system can perform EV battery charging, as well as energy injection into the power grid, through the connection with three main types of power grids (hence the designation of universal), namely: (1) Single-phase AC power grids; (2) Three-phase AC power grids; (3) DC power grids. The traction drive operation mode also comprises bidirectional operation, i.e., the system is able to perform regenerative braking when the EV motor acts as a generator, returning energy back to the EV batteries. The proposed integrated system was validated through computer simulations for the traction drive system and for the three distinct types of interface with the power grid. 
In all the referred operation modes, bidirectional operation was verified, which is an important contribution to the smart grids, and both slow and fast battery charging modes were addressed. Besides, the operation as a shunt active power filter and as an uninterruptible power supply (UPS) is also possible. Hence, besides having advantages in terms of multi-functionalities, the proposed system offers additional operation modes that are not considered in a traditional EV battery charging system.

Regarding future work, besides validating the other possible operation modes at a simulation level (shunt active power filter and UPS), the design phase will be a critical aspect of the developed work, since there are size and weight constraints for a system that has to be installed in an EV. Provided that external inductors will be needed to interface the system with the power grid, several aspects should be taken into consideration, such as the power semiconductor approach, switching frequency and inductance values, in order to accomplish a relatively compact solution for power levels of $50 \mathrm{~kW}$ or higher, which are the typical power values for an $\mathrm{EV}$.

\section{References}

1. J. Milberg and A. Schlenker, "Plug into the Future," IEEE Power and Energy Magazine, vol. 9, no. 1, pp. 56-65, Jan. 2011.

2. C. Gearhart and A. Breitenbach, "Connectivity and Convergence: Transportation for the 21st Century," IEEE Electrification Magazine, vol. 2, no. 2, pp. 6-13, Jun. 2014.

3. V. Torres-Sanz, J. A. Sanguesa, F. J. Martinez, P. Garrido, and J. M. Marquez-Barja, "Enhancing the Charging Process of Electric Vehicles at Residential Homes," IEEE Access, vol. 6, pp. 22875-22888, 2018.

4. J. H. Teng, S. H. Liao, and C. K. Wen, "Design of a fully decentralized controlled electric vehicle charger for mitigating charging impact on power grids," in IEEE Transactions on Industry Applications, 2017, vol. 53, no. 2, pp. 1497-1505.

5. K. Knezovic, S. Martinenas, P. B. Andersen, A. Zecchino, and M. Marinelli, "Enhancing the Role of Electric Vehicles in the Power Grid: Field Validation of Multiple Ancillary Services," IEEE Transactions on Transportation Electrification, vol. 3, no. 1, pp. 201-209, 2017.

6. R. Abousleiman and R. Scholer, "Smart Charging: System Design and Implementation for Interaction Between Plug-in Electric Vehicles and the Power Grid," IEEE Transactions on Transportation Electrification, vol. 1, no. 1, pp. 18-25, 2015.

7. J. de Hoog, T. Alpcan, M. Brazil, D. A. Thomas, and I. Mareels, "Optimal Charging of Electric Vehicles Taking Distribution Network Constraints Into Account," IEEE Transactions on Power Systems, vol. 30, no. 1, pp. 365-375, Jan. 2015.

8. S. I. Vagropoulos, D. K. Kyriazidis, and A. G. Bakirtzis, "Real-Time Charging Management Framework for Electric Vehicle Aggregators in a Market Environment," IEEE Transactions on Smart Grid, vol. 7, no. 2, pp. 1-1, 2015.

9. W. Kempton and J. Tomić, "Vehicle-to-grid power implementation: From stabilizing the grid to supporting large-scale renewable energy," Journal of Power Sources, vol. 144, no. 1, pp. 280-294, 2005.

10. V. Monteiro, J. G. Pinto, and J. L. Afonso, "Operation Modes for the Electric Vehicle in Smart Grids and Smart Homes: Present and Proposed Modes," IEEE Transactions on Vehicular Technology, vol. 65, no. 3, pp. 1007-1020, Mar. 2016.

11. C. Liu, K. T. Chau, D. Wu, and S. Gao, "Opportunities and challenges of vehicle-tohome, vehicle-to-vehicle, and vehicle-to-grid technologies," Proceedings of the IEEE, vol. 101, no. 11, pp. 2409-2427, 2013. 
12. V. Monteiro, B. Exposto, J. C. Ferreira, and J. L. Afonso, "Improved Vehicle-to-Home (iV2H) Operation Mode: Experimental Analysis of the Electric Vehicle as Off-Line UPS," IEEE Transactions on Smart Grid, vol. 8, no. 6, pp. 2702-2711, 2017.

13. M. Kesler, M. C. Kisacikoglu, and L. M. Tolbert, "Vehicle-to-grid reactive power operation using plug-in electric vehicle bidirectional offboard charger," IEEE Transactions on Industrial Electronics, vol. 61, no. 12, pp. 6778-6784, 2014.

14. R. Hou and A. Emadi, "Applied Integrated Active Filter Auxiliary Power Module for Electrified Vehicles With Single-Phase Onboard Chargers," IEEE Transactions on Power Electronics, vol. 32, no. 3, pp. 1860-1871, Mar. 2017.

15. V. Monteiro, G. Pinto, and J. L. Afonso, "Experimental Validation of a Three-Port Integrated Topology to Interface Electric Vehicles and Renewables with the Electrical Grid," IEEE Transactions on Industrial Informatics, vol. 3203, no. c, pp. 1-1, 2018.

16. J. Ansari, A. Gholami, A. Kazemi, and M. Jamei, "Environmental/economic dispatch incorporating renewable energy sources and plug-in vehicles," IET Generation, Transmission \& Distribution, vol. 8, no. 12, pp. 2183-2198, Dec. 2014.

17. W. Rippel, "Integrated traction inverter and battery charger apparatus," US4920475A, 1990.

18. W. Rippel and A. Cocconi, "Integrated motor drive and recharge system," US5099186A, 1992.

19. A. Cocconi, "Combined motor drive and battery charger system," US5341075A, 1994.

20. M. Yilmaz and P. T. Krein, "Review of Battery Charger Topologies, Charging Power Levels, and Infrastructure for Plug-In Electric and Hybrid Vehicles," IEEE Transactions on Power Electronics, vol. 28, no. 5, pp. 2151-2169, May 2013.

21. D. Thimmesch, "An SCR Inverter with an Integral Battery Charger for Electric Vehicles," IEEE Transactions on Industry Applications, vol. IA-21, no. 4, pp. 1023-1029, Jul. 1985.

22. L. Solero, "Nonconventional on-board charger for electric vehicle propulsion batteries," IEEE Transactions on Vehicular Technology, vol. 50, no. 1, pp. 144-149, 2001.

23. Lixin Tang and Gui-Jia Su, "A low-cost, digitally-controlled charger for plug-in hybrid electric vehicles," in 2009 IEEE Energy Conversion Congress and Exposition, 2009, pp. 3923-3929.

24. S. Haghbin, S. Lundmark, M. Alakula, and O. Carlson, "Grid-Connected Integrated Battery Chargers in Vehicle Applications: Review and New Solution," IEEE Transactions on Industrial Electronics, vol. 60, no. 2, pp. 459-473, Feb. 2013.

25. H. C. Chang and C. M. Liaw, "Development of a compact switched-reluctance motor drive for EV propulsion with voltage-boosting and PFC charging capabilities," IEEE Transactions on Vehicular Technology, vol. 58, no. 7, pp. 3198-3215, 2009.

26. I. Subotic, N. Bodo, and E. Levi, "An EV Drive-Train with Integrated Fast Charging Capability," IEEE Trans. on Power Electronics, vol. 31, no. 2, pp. 1461-1471, 2016.

27. C. Liaw and H. Chang, "An integrated driving/charging switched reluctance motor drive using three-phase power module", IEEE Transactions on Industrial Electronics, vol. 58, no. 99, pp. 1-1, 2010.

28. D. H. Kim, M. J. Kim, and B. K. Lee, "An integrated battery charger with high power density and efficiency for electric vehicles," IEEE Transactions on Power Electronics, vol. 32, no. 6, pp. 4553-4565, 2017.

29. I. Subotic, N. Bodo, and E. Levi, "Single-phase on-board integrated battery chargers for EVs based on multiphase machines," IEEE Transactions on Power Electronics, vol. 31, no. 9, pp. 6511-6523, 2016.

30. D. Chapman, "The Cost of Poor Power Quality," Power Quality Application Guide, no. 0b, p.8, 2001. Available: http://www.cda.org.uk.

31. M. McGranaghan and B. Roettger, "Economic evaluation of power quality," IEEE Power Engineering Review, vol. 22, no. 2, pp.8-12, 2002. 